\title{
Taxonomic problems in the subgenus Meloehelea Wirth of the genus Atrichopogon Kieffer (Diptera: Ceratopogonidae) inferred from both morphological and molecular characters
}

\author{
Andrea Tóthová, Jan Knoz, Radim Sonnek, Josef Bryja \& Jaromír Vaňhara
}

Tóthová, A., Knoz, J., Sonnek, R., Bryja, J. \& Vaňhara, J. 2008: Taxonomic problems in the subgenus Meloehelea Wirth of the genus Atrichopogon Kieffer (Diptera: Ceratopogonidae) inferred from both morphological and molecular characters. - Entomol. Fennica 19: 1-12.

The classification of Meloehelea (Ceratopogonidae) species is based on morphological characters. The taxonomic revision of generally well-known species recovered interesting facts on possible geographic intraspecific variability or on the presence of an additional valid species. In this study, 5 European species and 2 species from the U.S.A. and Canada have been compared based on their morphological characters. Subsequently, the $16 \mathrm{~S}$ rDNA sequences analyses of well known European species have been performed to confirm the characters mentioned in the determination key of this subgenus. Although, this study was limited by the number of examined non-European specimens, it provides some interesting facts on the possible morphological variability of well-known species and also an initial phylogenetic backbone for the progressive reconstruction of infrageneric relationships within the genus Atrichopogon.

A. Tóthová, R. Sonnek, J. Vaňhara, Masaryk University, Faculty of Science, Department of Botany and Zoology, Kotlářská 2, 61137 Brno, Czech Republic; A. Tóthová'se-mail: tothova@sci.muni.cz

J. Knoz, Masaryk University, Faculty of Science, Department of Experimental Biology, Kotlářská 2, 61137 Brno, Czech Republic

J. Bryja, Department of Vertebrate Biology, Academy of Sciences CR, 67502 Studenec 122, Czech Republic; Masaryk University, Faculty of Science, Institute of Botany and Zoology, Kotlářská 2, 61137 Brno, Czech Republic

Received 8 January 2007, accepted 7 June 2007

\section{Introduction}

The subgenus Meloehelea Wirth of the genus Atrichopogon Kieffer contains a group of biting midges that suck haemolymph from Meloidae and related beetles. This subgenus currently includes 16 species (Szadziewski \& Borkent 2004, Remm 1988, Wirth 1980) of which 12 spp. occur in the Palaearctic and $7 \mathrm{spp}$. in the Nearctic re- gion. These species are usually distinguished on the basis of morphological characters such as TR (tarsal ratio), number of mandible teeth, proboscis section length etc. (Wirth 1956, 1980, Szadziewski et al. 1995).

During an extensive biomonitoring study in North-western Bohemia (Bílina Area) and in Southern Moravia (Podyjí National Park) in the Czech Republic (1997-1999 and 2001-2003) 
that was focused on most dipteran families, we obtained material of three biting midge species of the subgenus Meloehelea, i.e. Atrichopogon (Meloehelea) winnertzi Goetghebuer, 1922, Atrichopogon (Meloehelea) lucorum (Meigen, 1818) and Atrichopogon (Meloehelea) oedemerarum Storå, 1939. Based on a morphometric analysis several additional specimens were identified as $A$. (M.) epicautae Wirth, 1956 following the key by Wirth (1980). Our material from Central Europe was morphologically compared with the type material of $A$. (M.) epicautae and additional specimens of $A(M$.) lucorum from the U.S. National Museum of Natural History (USNM) (Washington), the Canadian National Collection (Ottawa) and from prof. William Grogan (Salisbury University, Maryland). The American species A. (M.) downesi Wirth, 1980 and $A$. (M.) farri Wirth, 1956 are clearly characterised and are not included in this study, which also applies to $A$. (M.) atriscapulus Kieffer, 1918. Due to the recent knowledge, we consider both species $A$. (M.) winnertzi Goetghebuer, 1922 and $A$. (M.) meloesugans Kieffer, 1922 as valid (Szadziewski, pers. comm.).

Subsequently, we performed a DNA analysis comparing all Czech species of Meloehelea using DNA sequences of mitochondrial $16 \mathrm{~S}$ rDNA. The problems with species identification together with enormous practical importance of the group necessitate more accurate tools for the classification and identification of biting midges (Gomulski et al. 2005, Pages \& Monteys 2005). The use of molecular data to resolve taxonomical problems within the family has been very scarce and the published studies include almost exclusively the genus Culicoides Latreille, 1809 because of its medical importance (Sebastiani et al. 2001, Linton et al. 2002, Gomulski et al. 2005, 2006, Pages \& Monteys 2005, Perrin et al. 2006). In these studies, RAPD, enzymatic restriction of the COI gene and ITS regions 1 and 2 were used for differentiation of sibling species complexes. The first two methods do not seem too reliable and credible to solve these taxonomic problems. Mitochondrial (16S, COI, cytB) and nuclear genes (ITS1) have been used to solve intrageneric taxonomic inconsistencies in other dipteran families, (Pestano et al. 2003, Krüger et al. 2000, Guryev et al. 2001) and it is reasonable to test the useful- ness of these markers also in biting midges.

In the only study focusing on the phylogenetic relationships within Ceratopogonidae based on molecular data, sequences of the cox 2 gene were analysed. These results supported the monophyly of the family as well as the recent general classification based on morphological characters (Beckenbach \& Borkent 2003).

\section{Material and methods}

The specimens of own collection were mounted into microscope slides and examined using an Olympus BX51 microscope. The material was collected by various methods excluding attraction to light (for more details see Tóthová et al. 2004, 2005). Drawings and pictures were prepared using the same microscope with the SW MicroImage v. 4.0. For DNA analyses, the abdomen and thoracic musculature were removed for further processing and the reminder of each specimen was deposited as voucher specimen at the Department of Botany and Zoology (Masaryk University Brno, Czech Republic).

\subsection{Specimens examined}

The following characters were measured: AR antennal ratio; $\mathrm{CR}$ - costal ratio, $\mathrm{PR}$ - palpal ratio, PR-N - palpal ratio used in this study, see below, $\mathrm{R} 2 / \mathrm{R} 1$ - radial field ratio, TR - tarsal ratio.

\subsubsection{Atrichopogon (Meloehelea) epicautae, sensu Wirth, 1956}

The following specimens were examined: $1-5$, Paratype females; 6-8, females from Canada; 911, females from Arizona (see Table 1):

- 1-4, Rustlers Park, Chiricahua Mts., Arizona, 25.VI.1953, leg. Wirth, attacking Meloe beetles

- 5, Rustlers Park, Chiricahua Mts., Arizona, 25.VI.1953, leg. Wirth, attacking Meloe beetles (drawn and measured in Wirth 1980)

- 6, Kouchibouguac National Park, N.B., 10.VII.1978, coll. L. Forster, No. J.A.D. $1194 / 1 / 29$ 
Table 1. Measurements of the females (1-11) of Atrichopogon epicautae examined. Abbreviations: AR: antennal ratio, CR: costal ratio, PR: palpal ratio, PR-N: palpal ratio used in this study, R2/R1: radial field ratio, Wing: wing length in $\mathrm{mm}$, Mt: number of mandible teeth, TR: tarsal ratio, MuB: macrotrichia under the basal field of the wing.

\begin{tabular}{llllllllll}
\hline & AR & CR & PR & PR-N & R2/R1 & Wing & Mt & TR & MuB \\
\hline 1 & 1.8 & 0.68 & 2.75 & 5.12 & 2.27 & 1.38 & 19 & 2.29 & no \\
2 & 1.82 & 0.66 & 2.66 & 4.11 & 2.41 & 1.29 & 18 & 2.24 & no \\
3 & 2.17 & 0.66 & 2.76 & 5.29 & 2.30 & 1.38 & 17 & 2.28 & no \\
4 & 1.97 & 0.65 & 2.63 & 4.63 & 2.82 & 1.34 & 18 & 2.31 & no \\
5 & 2.09 & 0.65 & 2.9 & 4.46 & 2.90 & 1.4 & 16 & 2.14 & no \\
6 & 2.04 & 0.68 & 2.85 & 3.3 & 2.85 & 1.18 & 19 & 2.22 & yes \\
7 & 1.98 & 0.68 & 2.76 & 3.88 & 2.51 & 1.08 & 16 & 2.3 & yes \\
8 & 1.94 & 0.7 & 2.66 & 3.89 & 2.76 & 1.2 & 18 & 2.44 & yes \\
9 & 2.46 & 0.65 & 3.13 & 5.42 & 2.54 & 1.32 & 17 & 2.27 & no \\
10 & 2.25 & 0.65 & 3.08 & 5.02 & 2.38 & 1.16 & 18 & 2.27 & no \\
11 & 1.84 & 0.69 & 2.63 & 3.7 & 2.7 & 1.2 & 17 & 2.40 & yes \\
\hline
\end{tabular}

- 7, Kouchibouguac National Park, N.B., 2.13.VII.1977, coll. J.R. Vockeroth, No. J.A.D. $1157 / 2 / 8$

- 8, White face Mt., N.Y., 79-506, 10.VII.1979, coll. D.F.J. Hilton, No. J.A.D. 1237/1/4

- 9, Yavapai Co. Ariz., A77-61, Red Rock Crossing, 19.VII.1977, M.W. Sanderson LT, leg. Wirth

- 10, Coconino Co. Ariz., A77-82 Oak Creek, Cumphouse Wash., 26.VIII.1977, M.W. Sanderson, BLT, leg. Wirth

- 11, Cranberry L., N.Y., St. Lawrence Co., 25.VI.1963, swamp, leg. Wirth.

\subsubsection{Atrichopogon (Meloehelea) lucorum} (Meigen, 1818)

The following specimens were examined: $1-5$, females from Smithsonian Inst.; 6-8, females from Canada; 9-10, females from Maryland, USA; 11-14, females of other European species of the subgenus Meloehelea (see Table 2):

- 1, England, Wylam Northumberland, N. bank Tyne, 6.V.1960, leg. D.A. Humphries, attacking Meloe beetles

- 2, Scotland, Aberlady Bay, 4. VI. 1964,

Table 2. Females of Atrichopogon lucorum (1-10) and other European species of the subgenus Meloehelea examined. 1-10: A. lucorum, 11: A. "epicautae", 12: A. meloesugans, 13: A. oedemerarum, 14: A. orbicularis, 15: A. winnertzi. Abbreviations as in Table 1.

\begin{tabular}{llllllllll}
\hline & AR & CR & PR & PR-N & R1/R2 & Wing & Mt & TR & MuB \\
\hline 1 & 2.76 & 0.78 & 3.3 & 5.84 & 3.24 & 1.41 & 22 & 2.6 & yes \\
2 & 2.74 & 0.7 & 2.99 & 5.33 & 3.6 & 1.52 & 23 & 2.46 & yes \\
3 & 2.49 & 0.66 & 3.04 & 5.7 & 3.22 & 1.41 & 17 & 2.25 & no \\
4 & 2.71 & 0.7 & 3.01 & 4.84 & 3.24 & 1.43 & 19 & 2.4 & yes \\
5 & 2.87 & 0.68 & 3.14 & 5.64 & 3.02 & 1.6 & 20 & 2.36 & yes \\
6 & 1.97 & 0.7 & 4.09 & 5.68 & 2.33 & 1.53 & 23 & 2.4 & 4 \\
7 & 2.28 & 0.66 & 3.9 & 5.67 & 2.25 & 1.55 & 30 & 2.44 & 4 \\
8 & 2.3 & 0.67 & 3.8 & 5.80 & 2.3 & 1.51 & 26 & 2.3 & no \\
9 & 2.21 & 0.73 & 2.94 & 5.23 & 2.71 & 1.3 & 21 & 2.64 & yes \\
10 & 2.17 & 0.69 & 3.17 & 5.40 & 3.16 & 1.28 & 19 & 2.48 & yes \\
11 & 2.76 & 0.7 & 2.7 & 4.97 & 2.96 & 1.40 & 18 & 2.29 & 3 \\
12 & 1.8 & 0.66 & 3.9 & 5.63 & 2.54 & 1.45 & 25 & 2.48 & 3 \\
13 & 1.6 & 0.7 & 3.61 & 5.62 & 2.84 & 1.53 & 16 & 2.57 & yes \\
14 & 2.45 & 0.74 & 3.46 & 5.63 & 2.5 & 1.73 & 27 & 2.38 & yes \\
15 & 2.97 & 0.7 & 4.27 & 8.94 & 2.31 & 1.50 & 36 & 2.57 & yes \\
\hline
\end{tabular}


Table 3. Collection sites and GenBank sequence accession numbers of biting midges used in the DNA analyses in this study.

\begin{tabular}{lll}
\hline Species & Collected in & \multirow{2}{*}{$16 \mathrm{~S}$} \\
\hline Dasyhelea saxicola Edwards, 1929 & Podyji NP, Czech Republic & DQ364965 \\
Atrichopogon lucorum 1 Meigen, 1818 & Podyji NP, Czech Republic & DQ364959 \\
Atrichopogon lucorum 2 Meigen, 1818 & Šumava NP, Czech Republic & DQ364960 \\
Atrichopogon lucorum 3 Meigen, 1818 & Šumava NP, Czech Republic & DQ364961 \\
Atrichopogon lucorum 4 Meigen, 1818 & Šumava NP, Czech Republic & DQ364962 \\
Atrichopogon lucorum 5 Meigen, 1818 & Jizerské hory PLA, Czech Republic & EF472587 \\
Atrichopogon aff. epicautae 1 & Podyji NP, Czech Republic & DQ364958 \\
Atrichopogon aff. epicautae 2 & Podyji NP, Czech Republic & DQ364964 \\
Atrichopogon winnertzi Goetghebuer, 1922 & Podyji NP, Czech Republic & DQ364957 \\
Atrichopogon oedemerarum 1 Storå, 1939 & Podyjí NP, Czech Republic & DQ364966 \\
Atrichopogon oedemerarum 2 Storå, 1939 & Podyji NP, Czech Republic & DQ364963 \\
\hline
\end{tabular}

Abdullah, R. \& E. Crowson, coll. at cantharidin

- 3, Arizona, Rustlers Park, Chiricahua Mts., 11.VII.1958, O’Brien \& Ross, light trap

- 4, England, Wylam Northumberland, N. bank Tyne, 6.V. 1960, leg. D.A. Humphries, attacking Meloe beetles

- 5, Scotland, Gale, 9.VI.1964, R. \& E. Crowson, coll. at cantharidin

- 6, Glacier Cr., B.C., 10 m, N. Terrace, 2.VI.1960, coll. W.W. Moss, No. J.A.D. $1238 / 5 / 2$

- 7, Glacier Cr., B.C., $10 \mathrm{~m}, \mathrm{~N}$. Terrace, 2.VI.1960, coll. W.W. Moss, No. J.A.D. $1238 / 5 / 1$

- 8, Shames B.C., $18 \mathrm{~m}$ SW. Terrace, 23.VI.1960, coll. C.H. Mann, No. J.A.D. $1238 / 4 / 1$

- 9, Maryland, Prince George Co. Patuxent Wildlife Refuge, 19.V.1979, malaise trap, leg. Wirth

- 10, Maryland, Prince George Co. Patuxent Wildlife Refuge, 23.V.1979, malaise trap, leg. Wirth

- 11, A. "epicautae", Podyjí NP, Czech Republic, 31.V.-1.VI.2001, car net, leg. Barták, coll. Tóthová

- 12, A. meloesugans, Wyskok, Poland, 1.VI. 2003, leg. Szadziewski, coll. Tóthová

- 13, A. oedemerarum, Bílina Area, Czech Republic, XI.1998-III.1999, malaise trap, leg. Barták, coll. Tóthová

- 14, A. orbicularis, Bieszczady, Poland, 22.VI.2004, leg. Gwizdalska, coll. Tóthová
- 15, A. winnertzi, Podyjí NP, Czech Republic, 26.VI.-24.VII.2001, malaise trap, leg. Barták, coll. Tóthová.

\subsection{DNA Extraction}

All the material used for DNA analysis (Table 3) was preserved in $95 \%$ ethanol. Individual flies or tissue portions were ground up in absolute ethanol, dried and rinsed in deionized water and placed in sterile Eppendorf tubes with extraction buffer (60 mM EDTA, 0.2\% SDS, $10 \mathrm{mM}$ Tris$\mathrm{HCL}, \mathrm{pH}=8)$ and pulverised in liquid nitrogen. After adding proteinase $\mathrm{K}$, samples were incubated at $56^{\circ} \mathrm{C}$ overnight. The DNA was extracted first with phenol:chloroform:isoamyl alcohol (25:24:1) and again with chloroform:isoamyl acohol (24:1). From the obtained solution, the DNA was finally extracted with the QIAQuick PCR Purification Kit (QIAGEN) following the manufacturer's protocol.

\subsection{Molecular analysis}

Modified primers mt32 (5'-CAACATCGAGGTCGC-3') and mt34 (5'-TTGACCGTGCAAAGGTAG-3') (Nirmala et al. 2001) were used for both amplification and sequencing the ca. $320 \mathrm{bp}$ long fragment of the mitochodrial $16 \mathrm{~S}$ rRNA gene. Amplifications were performed in a 20ul reaction mixture containing $1 \times$ PCR buffer (Fermentas), $2 \mathrm{mM} \mathrm{MgCl}, 1.2 \mathrm{U}$ Taq polymerase 


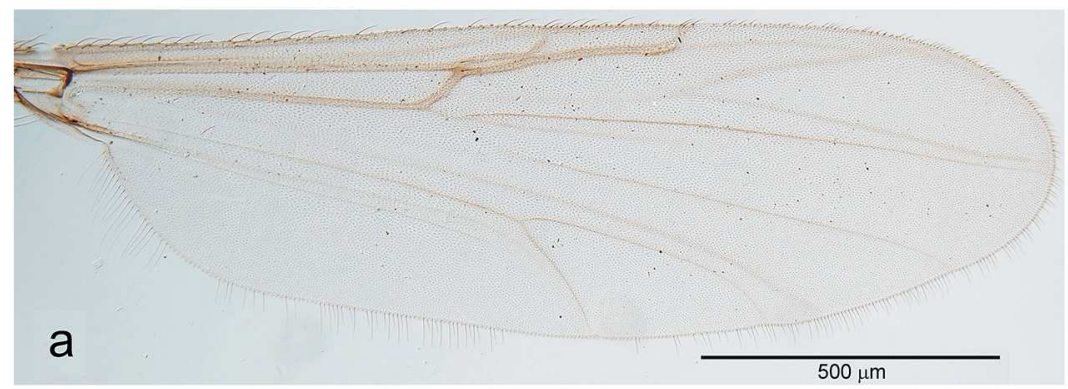

Fig. 1. Males identified by Wirth as $A$. epicautae. - a. Wing of the male drawn by Wirth (1980). - b. Hypopygium of the same specimen. - c. Hypopygium of a male from the same collection. $-d$. Infuscated eyes of the specimen drawn by Wirth (1980).
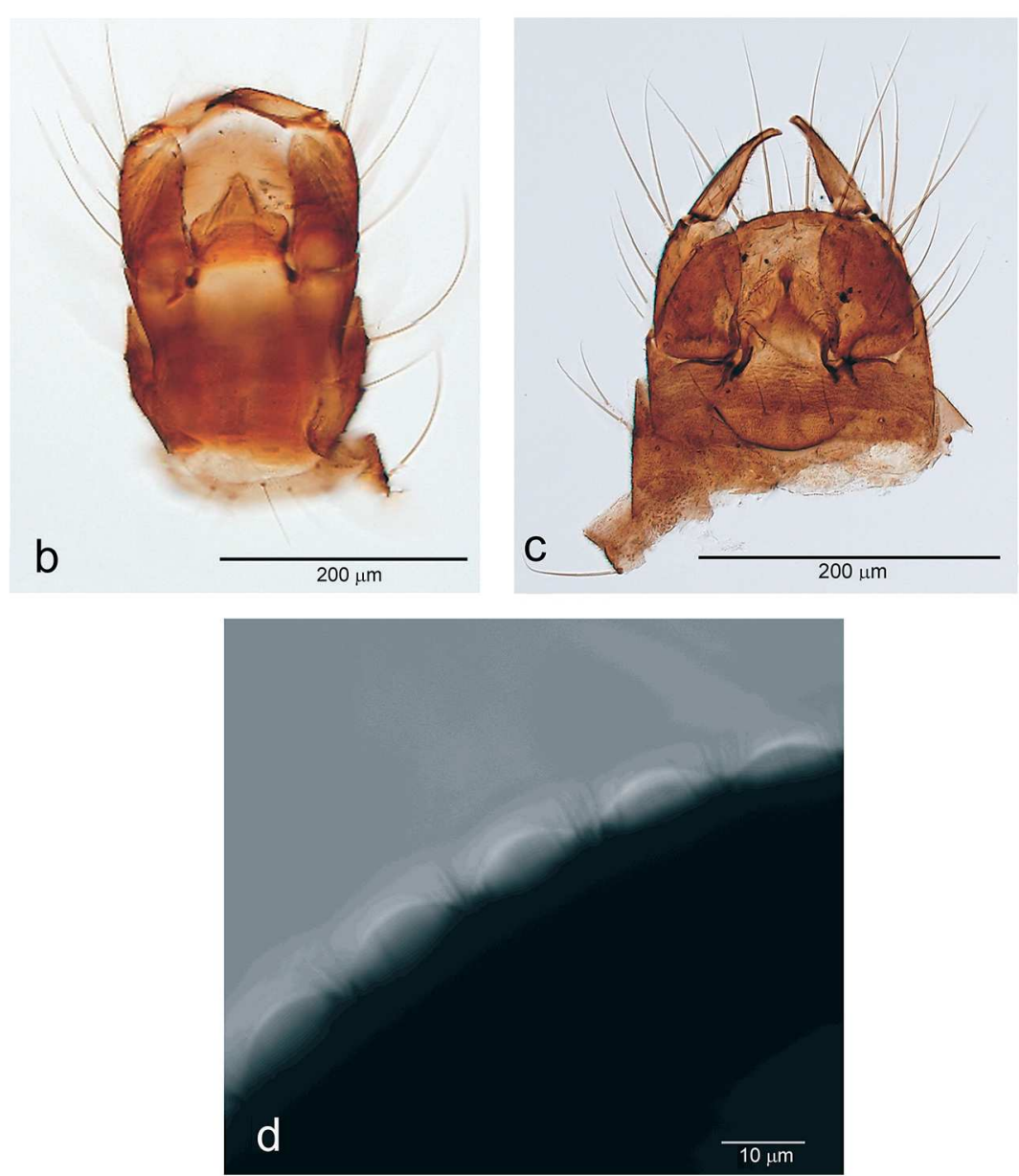

(Fermentas) and $4 \mathrm{uM}$ of each primer. Temperature cycling generally consisted of a 2 min initial denaturation at $94^{\circ} \mathrm{C}$, followed by $35-38$ cycles including $94^{\circ} \mathrm{C}$ for $30 \mathrm{~s}, 53^{\circ} \mathrm{C}$ for $30 \mathrm{~s}$ and $72^{\circ} \mathrm{C}$ for $1 \mathrm{~min} 30 \mathrm{~s}$ and final extension at $72^{\circ} \mathrm{C}$ for $7 \mathrm{~min}$. PCR reactions were performed in Robocycler Gradient 96 thermal cycler (Stratagene). All PCR products were visualized via agarose gel electrophoresis to assure proper amplification and detect possible contamination using negative controls. PCR products were purified using the QIAquick PCR Purification Kit (QIAGEN) and used directly for sequencing. The sequencing reactions were performed in a $10 \mathrm{ul}$ reaction mixture using the Big Dye Terminator v. 1.1. After the thermocycling, the reactions were purified by the EDTA/ethanol precipitation before the injection to the ABI310 Genetic Analyser (Applied 
Biosystems). Sequences were determined for both strands of the PCR product.

Species Dasyhelea saxicola (Edwards, 1929) from the sister tribe Dasyheleinae was used as out-group to root the phylogenetic trees (Table 3).

\subsection{Alignment and phylogenetic analysis}

Sequences of both strands were edited using Sequencher v. 4.5 (GeneCodes) and phylogenetic and molecular evolutionary analyses were conducted using MEGA version 3.1 (Kumar et al. 2004) and PAUP v.4.0b10 (Swofford 2002). The alignment was performed using ClustalW incorporated in MEGA v. 3.1 with the default settings. Phylogenetic relationships were reconstructed using maximum parsimony (MP), neighbourjoining with HKY85 substitution model (NJ) and maximum likelihood (ML) methods. Maximum parsimony heuristic searches for optimum trees were performed by swapping branches using the tree bissection reconnection (TBR) algorithm for 500 replicates, with all substitutions given equal weight and gaps treated as missing characters. Branch support was assessed by 1,000 bootstrap replicates. The ModelTest 3.8 on-line tool (Posada 2006) was used for testing and choosing the best model for likelihood analysis. The obtained trees were edited in TreeView (Page 1996) and the final layout was performed using Adobe Photoshop 8.0 CS.

\section{Results}

\subsection{Morphological characters}

Females of the subgenus Meloehelea have two seminal capsules, bare eyes and a short proboscis that is straight or bent anteriorly. The sensory pit on the third palpal segment is usually located at midlength. The proximal antennal flagellomers are broad and disciform, closely appressed and the teeth of the mandibles are largest at midportion.

Males have a more or less uniformly coloured scutum. Their proboscis is shorter than head height, straight or bent anteriorly. A sensory pit is

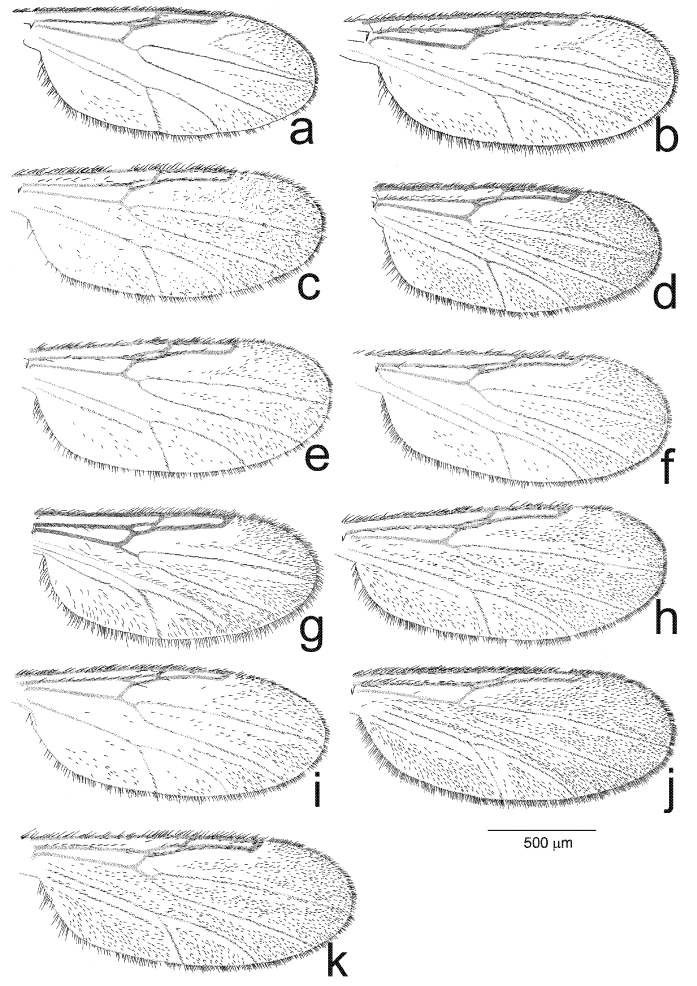

Fig. 2. Wings of the specimens of the subgenus Meloehelea examined. - a. A. epicautae paratype. - b. A. epicautae from Canada (Kouchibouguac National Park). - c. Specimen from the Czech Republic identified as $A$. epicautae. - d. A. lucorum from Scotland. - e. A. lucorum from Canada (Glacier Creek, B.C.). - f. A. lucorum from Canada (Shames B.C.). - g. A. lucorum from Maryland, USA. - h. A. oedemerarum from the Czech Republic. - i. A. meloesugans from Poland. $-\mathrm{j}$. A. orbicularis from Poland. k. A. winnertzi from the Czech Republic.

located at midlenght or near to the apex of the third palpal segment. Genitalia are not enlarged, as broad as the tip of the abdomen, gonostylus with simple pointed apex. Wing membrane is with macrotrichia, eyes bare. Interesting is the fact, that the male of Atrichopogon (Meloehelea) epicautae, described by Wirth (1956), has pubescent eyes and its hypopygium is very similar to those of the subgenus Atrichopogon. This is probably a missidentification and male specimens described as $A$. (M.) epicautae sensu Wirth (1980) need to be re-evaluated. For example, two males identified as $A$. (M.) epicautae on loan of the Smithsonian Institution are not similar. Both 

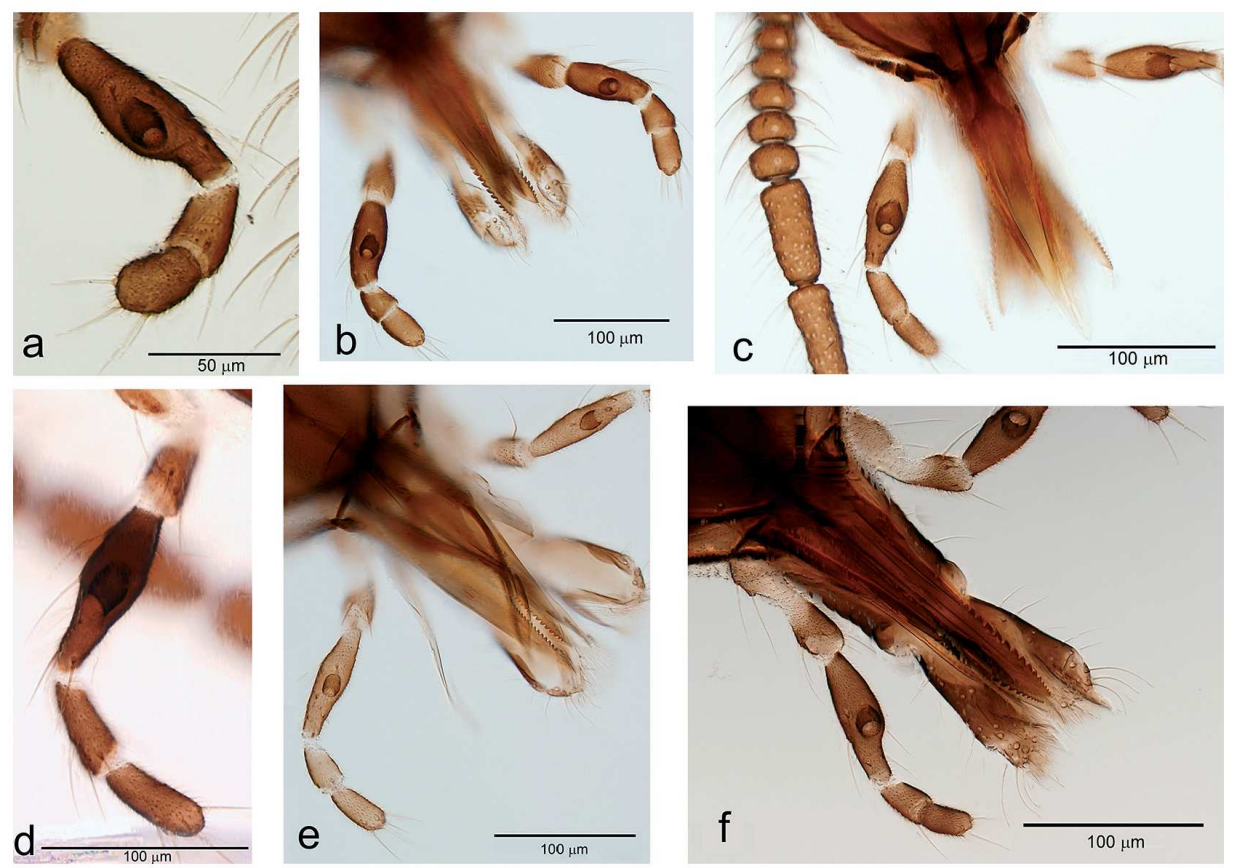

Fig. 3. Palps and mouthparts of examined specimens of the subgenus Meloehelea. - a. A. epicautae paratype. - b. A. epicautae from Canada (Kouchibouguac National Park). - c. Specimen from the Czech Republic identified as A. epicautae. - d. A. lucorum from Scotland. - e. A. lucorum from Canada (Glacier B.C.). - f. A. Iucorum from Maryland, USA.
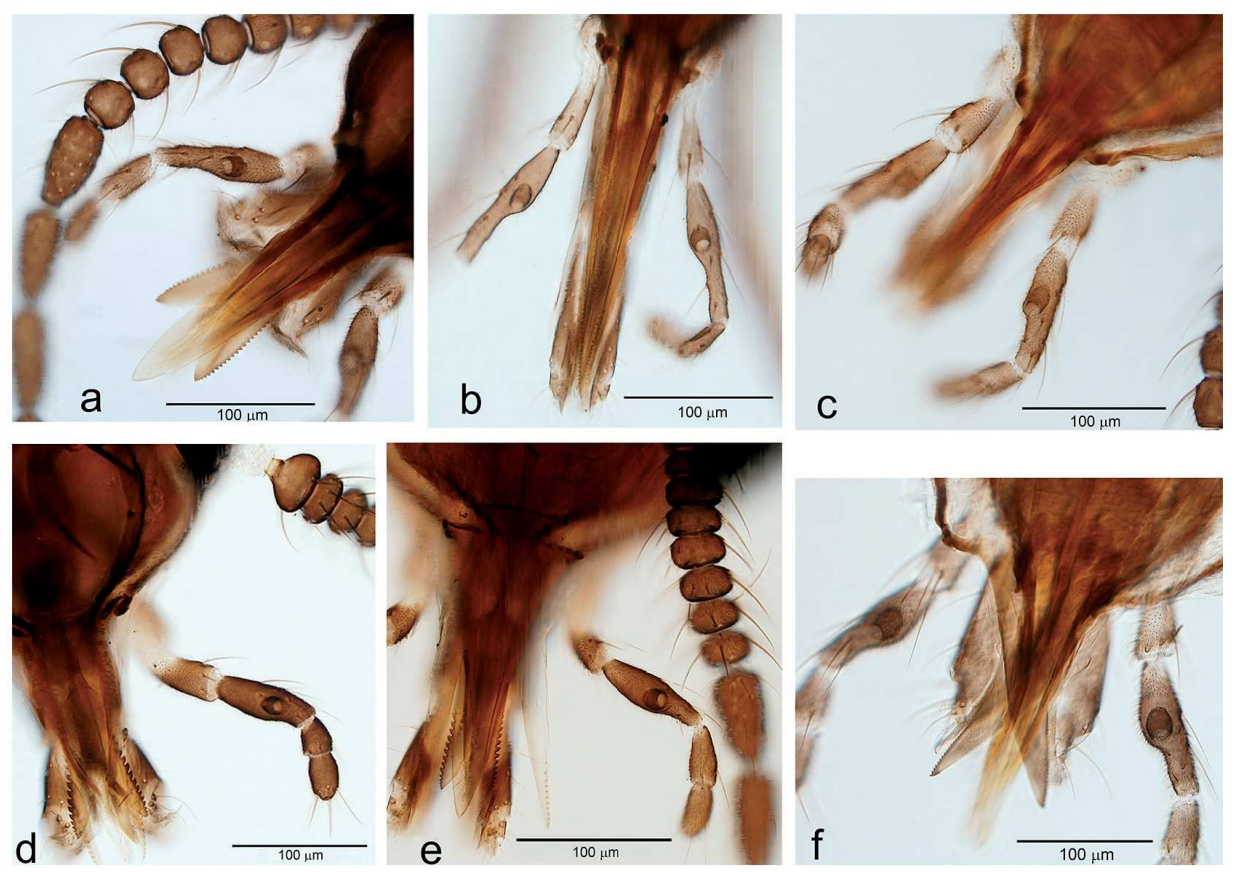

Fig. 4. Palps and mouthparts of examined specimens of the subgenus Meloehelea. - a. A. meloesugans from Poland. $-\mathrm{b}$. A. winnertzi from the Czech Republic. $-\mathrm{c}$. A. oedemerarum from the Czech Republic. - d. A. epicautae from Cranberry Lake, N.Y., St. Lawrence Co. - e. A. lucorum from Arizona. - f. A. orbicularis from Poland. 
males have pubescent eyes, bare wings, but their genitalia are different (see Fig. 1a-d). The second radial cell is $1.78 \times$ and $2.5 \times$ (the specimen drawn by W.W. Wirth) longer than the first radial cell and the fifth palpal segment is rounded apically. All these characters are typical of the subgenus Atrichopogon (Szadziewski et al. 1995).

The analysis of the morphological characters of the Meloehelea specimens revealed several interesting facts.

1) The study of the paratype females of $A$. epicautae allows us to define their distinctive characters: absence of macrotrichia under B (see Fig. 2), R2/R1 ratio (up to 2.90) and the ratio of the length of the $3^{\text {rd }}$ palpal segment and its width on the distal third of the segment - PR-N ratio (4.11-5.29).

2) Canadian specimens of $A$. epicautae have many macrotrichia under the basal field (B), and PR-N $=3.3-3.89$, which is on the border with those of A. lucorum and paratypes of $A$. epicautae (see Figs 2-4).

3) The specimen from the Czech Republic identified as $A$. epicautae indicates very close relation to this species following Wirth's key. It has no macrotrichia under $\mathrm{B}$ and the R2/R1 ratio is 2.96 . However, the $303 \mathrm{bp}$ of $16 \mathrm{~S}$ rRNA gene sequence of this specimen was completely identical with those of $A$. lucorum from the Czech Republic. The identification of $A$. epicauate based on published characters is thus questionable.

4) The A. epicautae specimen no. 11 from Cranberry Lake, St. Lawrence Co. New York also lacks the typical characters of $A$. epicautae; it has numerous macrotrichia under B (see Fig. $5 a-b)$ and the shape of the $3^{\text {rd }}$ palpal segment is different of that of $A$. epicautae paratype (Fig. 6). That poses another question about the validity of this character, which might be subject to intraspecific variability. In other Meloehelea species the presence and abundance of macrotrichia on the wings appears to be a stable character.

5) The majority of material from the Smithsonian Inst. came from Europe (England, Scotland and Estonia). All of them were typical $A$. lucorum with numerous macrotrichia under $\mathrm{B}, \mathrm{TR}=2.34-2.6$, and PR-N $=4.84-5.84$. The
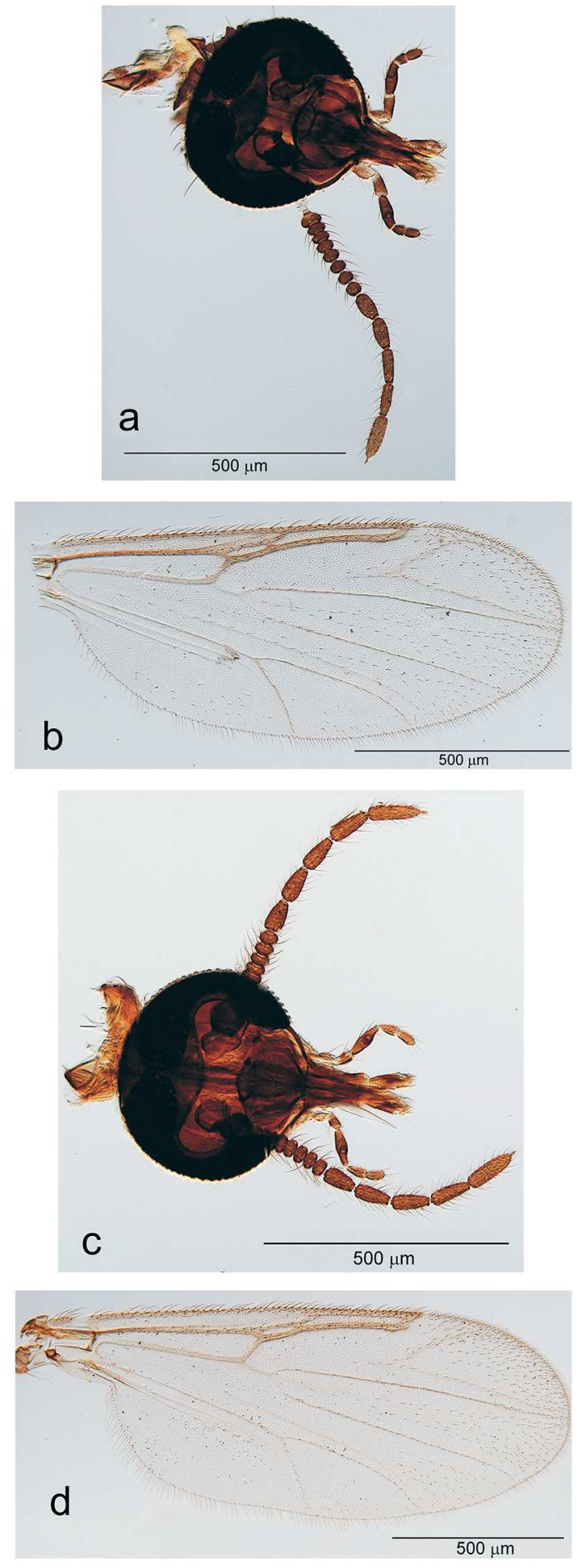

Fig. 5. Doubtfull specimens. - a. and b. A. epicautae (Cranberry Lake, N.Y., St. Lawrence Co.). - c. and d. A. lucorum (Arizona). 


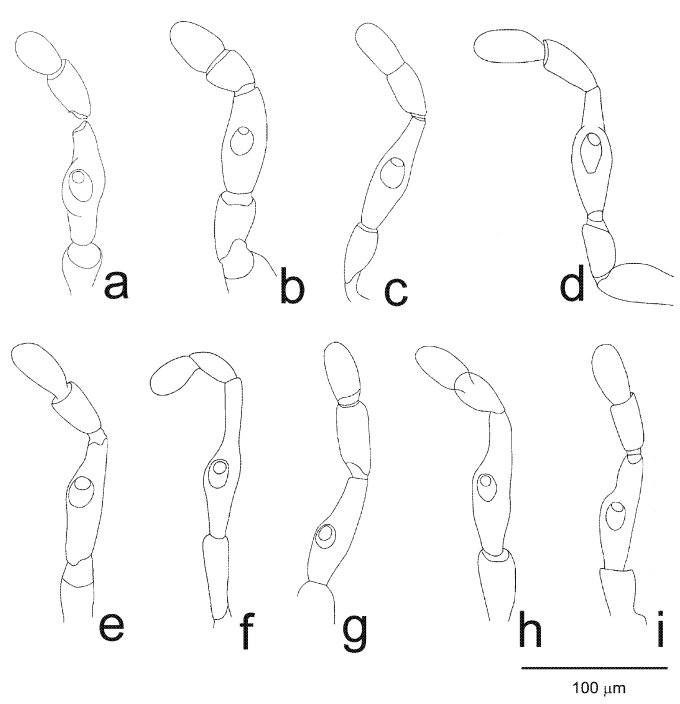

Fig. 6. Palps of examined specimens of the subgenus Meloehelea. - a. A. epicautae paratype. - b. A. epicautae from Canada (Kouchibouguac National Park). - c. Specimen from the Czech Republic identified as A. epicautae. - d. A. lucorum from Scotland. - e. A. lucorum from Canada (Shames B.C.). - f. A. winnertzi from the Czech Republic. - g. A. meloesugans from Poland. - h. A. oedemerarum from the Czech Republic. $-\mathrm{i}$. A. orbicularis from Poland.

specimen collected in the U.S.A. (Arizona) identified as A. lucorum had no macrotrichia under B (see Fig. 5c-d); however, on the basis of measurements alone, it is very close to $A$. lucorum. Similarly, the status of the Canadian A. lucorum is not clear. It has a $\mathrm{PR}=4$, inferring a relation to $A$. winnertzi. However, if we take PR-N (5.64-5.68) the Canadian specimens of $A$. lucorum fit in the typical "lucorum" group. This Canadian species has mandible teeth very similar to those of $A$. winnertzi (see Fig. 7), but has no (or only few) macrotrichia under $\mathrm{B}$ on the wing, which is another difference between $A$. lucorum and $A$. winnertzi.

6) There is no type male of $A$. epicautae. The male specimens collected and described by Wirth (1980) do not belong to the subgenus Meloehelea, as they have bare wings, infuscated eyes and their hypopygia are not similar (see Fig. 1a-d).

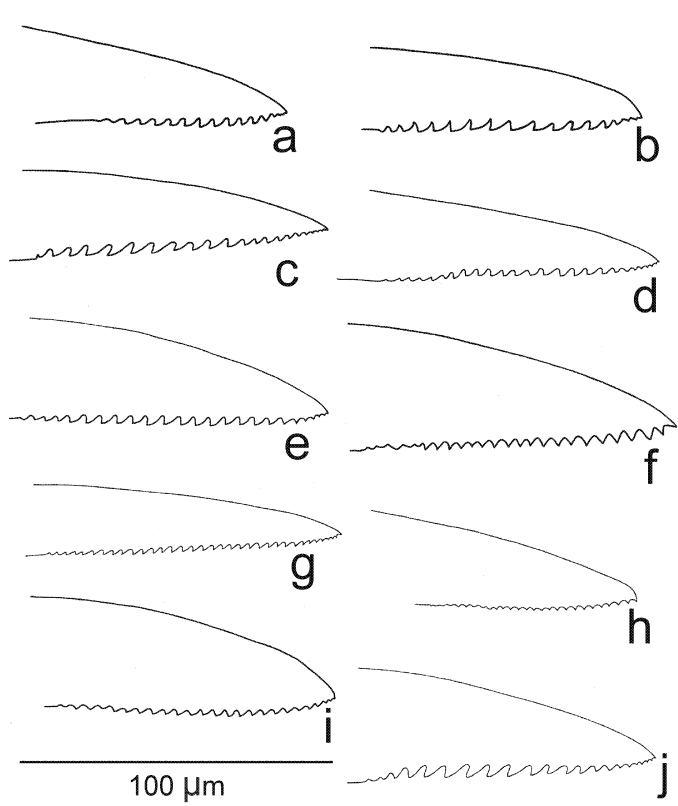

Fig. 7. Mandible teeth of examined specimens of the subgenus Meloehelea. - a. A. epicautae paratype. - b. A. epicautae from Canada (Kouchibouguac National Park). - c. A. lucorum from Scotland. - d. A. lucorum from Canada (Glacier Creek, B.C.). - e. A. lucorum from Canada (Shames B.C.). - f. A. oedemerarum from the Czech Republic. - g. A. winnertzi from the Czech Republic. - h. A. orbicularis from Poland. i. A. meloesugans from Poland. - j. Specimen from the Czech Republic identified as A. epicautae.

\subsection{Analysis of $16 \mathrm{~S}$ rDNA sequences}

The length of the $16 \mathrm{~S}$ rDNA resulting alignment was of 303 bp of which 222 were constant and 31 parsimony-informative. The alignment is available upon request from the senior author. By maximum parsimony PAUP found the single most parsimonious tree shown in Fig. 8. The hierarchical likelihood ratio test (IRT) as implemented in Modeltest 3.8 (online tool) suggested the use of the $\mathrm{F} 81+\mathrm{G}$ model for maximum likelihood analysis as optimal for this dataset (assumed nucleotide frequencies $\mathrm{A}=0.41610, \mathrm{C}=0.05560$, $\mathrm{G}=0.10530 \mathrm{~T}=0.42300$, rates $=$ gamma, shape $=$ $0.2072,-\ln L=726.18163$, pinvar $=0$ ) with 4 rates categories and a 50\% majority - rule consensus tree was performed (see Fig. 8). The topologies of all obtained trees were similar, only the different bootstrap values are shown above and below the 


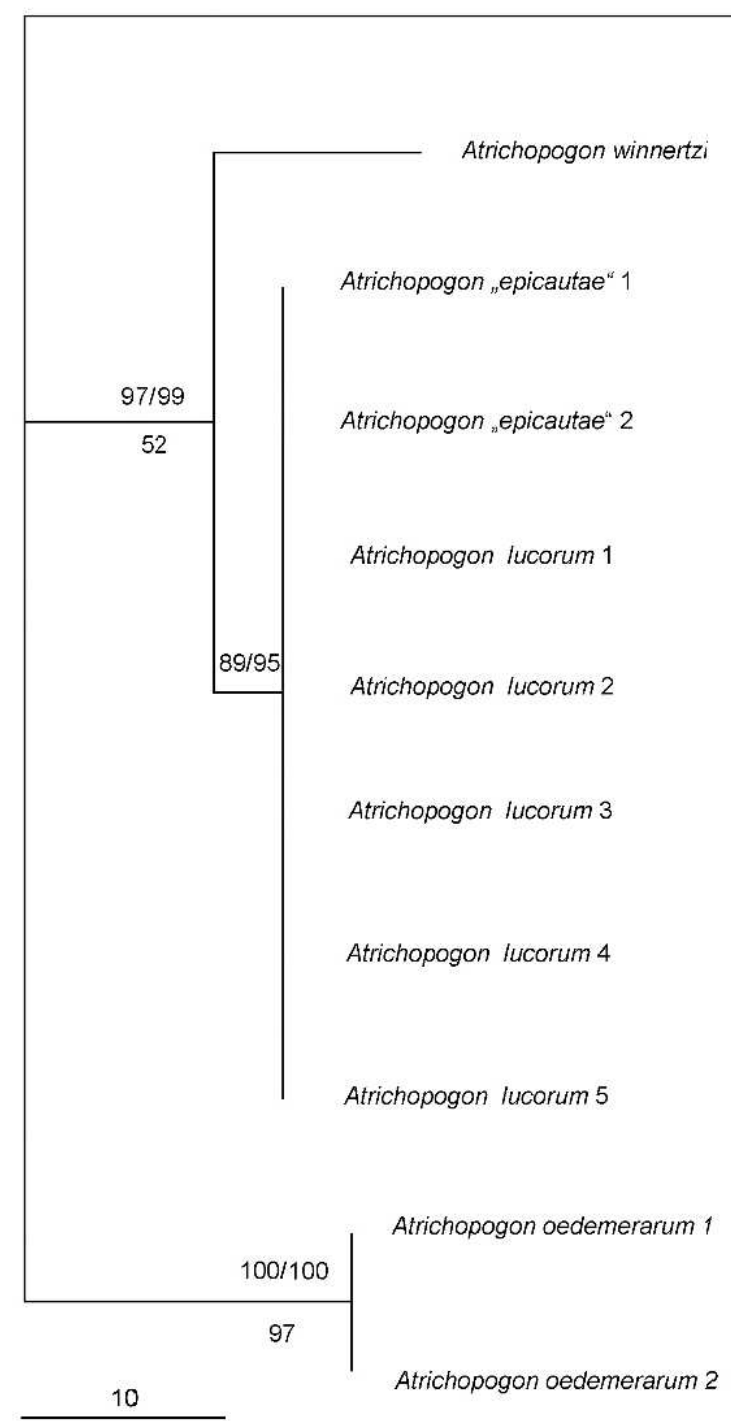

Fig. 8. Maximum parsimony tree for the included biting midge taxa obtained by analysing $16 S$ rDNA data set; the length $=94, \mathrm{Cl}$ excluding uninformative characters $=0.9524$, $\mathrm{Rl}=0.9565, \mathrm{RC}=09362$. Bootstrap values are shown above (maximum parsimony/neighbour-joining) and below (maximum likelihood) the branches $(1000$ replicates). Scale: 10 substitutions/site. branches. The pairwise distances using the HKY85 substitution model are shown in Table 4. The minimum evolution score of the NJ tree was 0.34910 . The interspecific variability of Meloehelea species with distance values varied between 5.6-14.5\%. All of the obtained phylogenetic trees fully correspond with the recent systematics of the subgenus Meloehelea based on the form of the proximal flagellomeres (Wirth 1980), however the analysed specimens of $A$. (M.) lucorum and $A$. (M.) "epicautae" were identical (pairwise-distance $0.00 \%$ among these two species). This result supports the usefulness of the $16 \mathrm{~S}$ gene on lower taxonomic levels. It means also the suitability of this morphological character mentioned above (shape of the proximal flagellomeres) in separation of main groups of the subgenus Meloehelea and incorrectness of the characters used for differentiation of species $A$. (M.) lucorum and $A$. (M.) epicautae (hind tarsal ratio, proboscis section length ratio). The pairwise distances support these facts, as well. The species $A$. oedemerarum is separated from the "lucorum" group by virtue of its moniliform flagellomeres; $A$. winnertzi is related to $A$. lucorum by their shared disciform flagellomeres but separated due to the number and shape of mandible teeth and PR (PR-N). The sequences of the 
Table 4. Pairwise distances of $16 \mathrm{~S}$ rDNA sequences using HKY85 substitution model.

\begin{tabular}{lllll}
\hline & D. saxicola & A. winnertzi & A. lucorum & A. oedemerarum \\
\hline D. saxicola & - & - & - & - \\
A. winnertzi & 0.28487 & - & - & - \\
A. lucorum & 0.23850 & 0.05611 & - & - \\
A. oedemerarum & 0.24668 & 0.14450 & 0.11471 & - \\
"A. epicautae" & 0.23850 & 0.05611 & 0.00000 & 0.11471 \\
\hline
\end{tabular}

mitochodrial $16 \mathrm{~S}$ gene of all analysed specimens of $A$. "epicautae" and A. lucorum were identical, so we did not detect any geographical variation in these. However, the characters used in the key by Wirth are doubtful and the segregation of these two species is probably incorrect. For the exact identification of the species in the subgenus Meloehelea it will be necessary to discover other characters that are not subject to intra- or interspecific variation (e.g. presence/absence of macrotrichia on the wing, $\mathrm{R} 2 / \mathrm{R} 1$ ratio, $\mathrm{PR}-\mathrm{N}$ ).

\section{Discussion}

We did examine the holotype of $A$. (M.) epicautae (type no. 62405 U.S.N.M) as well. Unfortunately, it was a pinned female specimen, so the characters used in this study were not available. Therefore we refer to the paratype females only. We documented no consistent pattern in both the presence of macrotrichia and morphometric characters frequently used for species identification in the subgenus Meloehelea. However, the specimens of the type series of $A$. epicautae and the typical specimens of $A$. lucorum from Scotland and Maryland have distinctive characters, which allow defining these species (macrotrichia under $\mathrm{B}$, shape of the $3^{\text {rd }}$ palpal segment, R2/R1 ratio, PR-N). Characters as CR, wing length, antennal ratio, shape of spermatheca (similar in all mentioned species) are not informative in the process of species determination. The problematic specimens of both species from Canada and of $A$. lucorum from Arizona could be the result of intraspecific variability. However, in case of the Canadian $A$. lucorum, it is probably a misidentification and these specimens represent a new species (their mandible teeth are completely different from those both of $A$. lucorum and A. epicautae).
The separation of $A$. lucorum and A. epicautae from other Meloehelea species is supported by the shape of the proximal flagellomeres, PR (PR$\mathrm{N})$ and the shape and number of mandible teeth.

All these results pose the following questions: (1) Are all of the above-mentioned species really valid taxonomic units or only evidence of extreme morphological variation within a single species? (2) Are there valid differences between European and Canadian (American) A. lucorum? The answer to these questions will require more material for morphological and genetic investigations as well as more data on the biology and distribution of this species. It is also necessary to discover the male of $A$. epicautae (if the validity of this species will be supported despite the intraspecific variablity) and to include it into the type series.

Acknowledgements. This study was supported by the research projects FRVS No. 1237/2005, PhD Research Fellowship of the Ministry of Education GA ČR 524/05/H536 and MSM No. 0021622416. The senior author is thankful to Ms. Holly Williams (U.S.N.M.), Dr. Jeffrey Cumming (CNCI) and Drs. A. Borkent, R. Szadziewski and W. Grogan for providing material of Meloehelea and for their comments on this article.

\section{References}

Beckenbach, A. T. \& Borkent, A. 2003: Molecular analysis of the biting midges (Diptera, Ceratopogonidae) based on mitochondrial cytochrome oxidase subunit 2 . - Mol. Phylogenet. Evol. 27: 21-35.

Gomulski, L. M., Meiswinkel, R. \& Delecolle, J. C. 2005: Phylogenetic relationships of the subgenus Avaritia Fox, 1955 including Culicoides obsoletus (Diptera, Ceratopogonidae) in Italy based on internal transcribed spacer 2 ribosomal DNA sequences. - Syst. Entomol. 30: 619-631.

Gomulski, L. M., Meiswinkel, R. \& Delecolle, J. C., Goffredo, M. \& Gasperi, G. 2006: Phylogeny of the sub- 
genus Culicoides and related species in Italy, inferred from internal transcribed spacer 2 ribosomal DNA sequences. - Med. Vet. Entomol. 20: 229-238.

Guryev, V., Makarevitch, I., Blinov, A. \& Martin, J. 2001: Phylogeny of the genus Chironomus (Diptera) inferred of mitochondrial cytochrome B and cytochrome oxidase I. - Mol. Phylogenet. Evol. 19: 9-21.

Krüger, A., Gelhaus, A. \& Garms, R. 2000: Molecular identification and phylogeny of east African Simulium damnosum s.l. and their relationships with West African species of the complex (Diptera: Simuliidae). - Insect Mol. Biol. 9: 101-108.

Kumar, S., Tamura, K. \& Nei, M. 2004: MEGA3: Integrated software for Molecular Evolutionary Genetics Analysis and sequence alignment. - Brief. Bioinform. 5: $150-163$.

Linton, Y.-M., Mordue (Luntz), A. J., Cruickshank, R. H., Meiswinkel, R., Mellor, P. S. \& Dallas, J. F. 2002: Phylogenetic analysis of the mitochondrial cytochrome oxidase subunit I gene of five species of the Culicoides imicola species complex. - Med. Vet. Entomol. 26: 139-146.

Nirmala, X., Hypša, V. \& Žurovec, M. 2001: Molecular phylogeny of Calyptratae (Diptera, Brachycera): the evolution of $18 \mathrm{~S}$ and $16 \mathrm{~S}$ ribosomal rDNAs in higher dipterans and their use in phylogenetic inference. - Insect Mol. Biol. 10; 475-485.

Page, R. D. 1996: TreeView: an application to display phylogenetic trees on personal computers. - Comput. Appl. Biosci. 12: 357-358.

Pages, N. \& Monteys, V. S. I. 2005: Differentiation of $\mathrm{Cu}$ licoides obsoletus and Culicoides scoticus (Diptera: Ceratopogonidae) based on mitochondrial cytochrome oxidase subunit I. — J. Med. Entomol. 6: 1026 1034.

Perrin, A., Cetre-Sossah, C., Mathieu, B., Baldet, T., Delecolle, J. C. \& Albina, E. 2006: Phylogenetic analysis of Culicoides species from France based on nuclear ITS1-rDNA sequences. - Med. Vet. Entomol. 20: 219-228.

Pestano, J., Brown, R. P., Suárez, N. P. \& Baéz, M. 2003: Diversification of sympatric Sapromyza (Diptera:
Lauxanidae) from Madeira: six morphological species but only four mtDNA lineages. - Mol. Phylogenet. Evol. 27: 422-428.

Posada, D. 2006: ModelTest Server: a web-based tool for the statistical selection of models of nucleotide substitution online. - Nucleic Acids Res. 34: W700-W703.

Remm, H. 1988: Family Ceratopogonidae. - In: Sóos, A. \& Papp, L. (eds.), Catalogue of Palearctic Diptera Vol. 3: pp. 11-110. Akadémia. Budapest, 401 pp.

Sebastiani, F., Meiswinkel, R., Gomulski, L. M., Guglielmino, C. R., Mellor, P. S., Malacrida, A.R. \& Gasperi, G. 2001: Molecular differentiation of the Old World Culicoides imicola species complex (Diptera, Ceratopogonidae) inferred using random amlified polymorphic DNA markers. - Mol. Ecol. 10: 1773-1786.

Swofford, D. L. 2002: PAUP* Phylogenetic Analysis Using Parsimony (* and Other Methods). Version 4 Beta 10. Sinauer Associates, Sunderland, Massachusetts.

Szadziewski, R. \& Borkent, A. 2004: Ceratopogonidae. In: de Jong H. (ed.), Fauna Europaea: Diptera Nematocera. Version 1.1. [www document]. URL http:// www.faunaeur.org/. (Site visited on $30 \mathrm{May}, 2007$ )

Szadziewski, R., Gilka, W. \&. Anthon, H. 1995: Immaturate stages of two European species of the subgenus Meloehelea (Diptera, Ceratopogonidae), with keys to the European subgenera of Atrichopogon. - Entomo1. Scand. 26: 181-190.

Tóthová, A., Barták, M. \& Knoz, J. 2004: Ceratopogonidae of Southern Moravia (NP Podyjí). - In: Bitušík P. (ed.), Acta Fac. Ecol. 12, Suppl. 1, Dipterologica bohemoslovaca 12: 143-148.

Tóthová, A., Knoz, J., Barták, M \& Kubík, Š. 2005: Biomonitoring of Ceratopogonidae (Diptera, Nematocera) using car-nets. - Entomol. Fennica 16:124-128.

Wirth, W. W. 1956: The biting midges ectoparasitic on blister beetles (Diptera, Heleidae). — P. Entomol. Soc. Wash. 58: 15-23.

Wirth, W. W. 1980: A new species and correction in the Atrichopogon midges of the subgenus Meloehelea attacking blister beetles (Diptera, Ceratopogonidae). P. Entomol. Soc. Wash. 82: 124-139. 